\title{
Study on Earthquake Disasters and Seismic Reinforcement Measures about Buildings of Different Structure Types
}

\author{
Guo Tingting ${ }^{1,2, a}, X X_{i w e i}^{3}, Y u$ Guihua $^{3}$ \\ 1Shandong Institute of Earthquake Engineering, Jinan, China \\ 2Earthquake Administration of Shandong Province, Jinan, China \\ 3Key Laboratory of Active Tectonics and Volcano, Institute of Geology, CEA, Beijing, China \\ a gtt.yy@163.com
}

Key words: earthquake; structure type; damage analysis; seismic reinforcement measures

Abstract. Different structure types of buildings have different structural characteristics and seismic performance. Earthquake disaster investigation and damage analysis results of different types of buildings can reflect the existing problems of China's urban residential buildings in the seismic structure design and construction process. This paper analyzes damage characteristics and earthquake disasters of main types of buildings, and can give seismic reinforcement measures of different types of buildings. It can be provided a reference for seismic performance survey and seismic reinforcement of Shandong province and nationwide buildings.

\section{Introduction}

At present, main types of China urban residential buildings are brick-wood structure, brick-concrete structure, brick-concrete structure of bottom frame and reinforced concrete frame structure. The different types of buildings have different building structure characteristics and seismic performance. In recent years, scholars at home and abroad have done a lot of research work and achievements in structure characteristics and seismic performance of different types of buildings[1-7].

Whether the existing codes and regulations for seismic design of buildings and kinds of seismic design of buildings can ensure that buildings' withstanding strong earthquake, will be tested in earthquake disaster. Great earthquake not only can test the seismic performance of buildings in the face of strong ground motion effect, but also can provide scientific research workers with a large number data of various types of building failure. In recent years, during the recent earthquake like 2008 Wenchuan 8.0 earthquake, 2010 Yushu, Qinghai 7.1 earthquake, 2013 Lushan 7.0 earthquake and 2014 Yutian 7.3 earthquake, different types of building damage and damage analysis results can reflect the existing problems of China's urban residential buildings in the aseismic structure design and construction process. Further researches and comprehensive analysis on design status and existing problems can obtain corresponding strengthening schemes and improvement measures for existing different types of buildings.

Through the method of combining field site investigation, collecting data, image processing and data analysis, damage characteristics and analysis of earthquake damage information are done, and aseismic reinforcement measures for all kinds of buildings are given further in this paper. It is suggested that research findings which can provide suggestions for seismic design and construction of urban residential buildings, and provide reference for seismic performance survey and seismic retrofitting of building of Shandong province and nationwide. 


\section{Damage characteristics and earthquake damage analysis of different types of buildings}

Main types of China urban residential buildings are brick-wood structure, brick-concrete structure, brick-concrete structure of bottom frame and reinforced concrete frame structure nowadays. This section will make investigation and discussion on damage characteristics of various types of buildings in earthquake disaster, and make damage analysis of the various types of buildings further.

\section{Damage characteristics and earthquake damage analysis of different types of buildings Brick-wood structure}

Brick-wood structure generally refers to the buildings which are constructed of the vertical load-bearing structure of the walls, columns constructed of brick or block, floor structure and roof by wooden. Due to its mechanical characteristics and engineering strength limit, general brick-wood structure is flat, up to 3 layers. The building foundation is built by rubble masonry, the buildings is mostly supported by brick, masonry wall and brick column, its roof is fitted with herringbone wooden frame, which is Placed by purlin, and laid by grass mud and tiles[8]. At present this kind of structure form in rural areas is still relatively common, its structure form is simple, and the building material is relatively cheap, but its whole structure and seismic performance is poor because of having no seismic structural measures

\section{Damage characteristics}

The brick-wood buildings in strong earthquake are severely damaged overall, and their earthquake characteristics are as follows: the roof tiles falling; wood truss damage, partial collapse or collapse, beam fracture and even collapse; the wall between windows appear a large number of "X" shear crack; the load wall crack, damage, and even collapse, and even houses collapse. Most of the buildings almost are structural damaged, even completely collapsed in the earthquake disaster area (X, XI intensity area) in this paper (Fig.1).

\section{Earthquake damage analysis}

The brick-wood building is a common structure form in rural areas. The seismic performance is poor, and its damage and collapse degree is very serious in X XI intensity area of Wenchuan earthquake. The main reasons are the following several aspects:

(1) The overall seismic performance of building is poor

Because there is no connection between the roof of brick-wood structure and the walls, weak connection between purlins and walls, and purlins and roof, so the overall performance of wood roof is poor. In the strong earthquake, because of the wall sway, then instability, the collapse of wood roof is caused. Because the horizontal and vertical wall are plain brick walls, and quality of interface at the junction of vertical and horizontal walls is poor, brick wall is severely damaged, and walls at the junction of vertical and horizontal walls can crack, even collapse vertically during earthquake The kind of structure has no anti-seismic structure design like reinforced concrete column, beam, so its overall seismic performance is poor, it cannot effectively resist the uneven earthquake damage on the wall.

(2) Malpractice of building material itself

Brick-wood structure mainly adopts brick, block masonry, which are brittle material, so its seismic performance is poor. Compared with the compressive strength, shear strength of brick masonry wall is poor itself; bonding between the bricks or blocks is mostly by lime mortar, so the 
bonding performance and shear capacity are all poor.

(3) The quality problems in the construction process

One of the important factors affecting shear capacity of brick-wood structure is quality of brick masonry, the main problems are as follows: low quality of cement mortar, insufficient cement, or inadequate cement grade, so that cement mortar strength is not up to standard; the plumpness of mortar is not enough, so that the integrity of the wall is poor. Moreover, Residents often secretly reduce wall thickness, even adopting $120 \mathrm{~mm}$ of the brick wall in order to save cost.

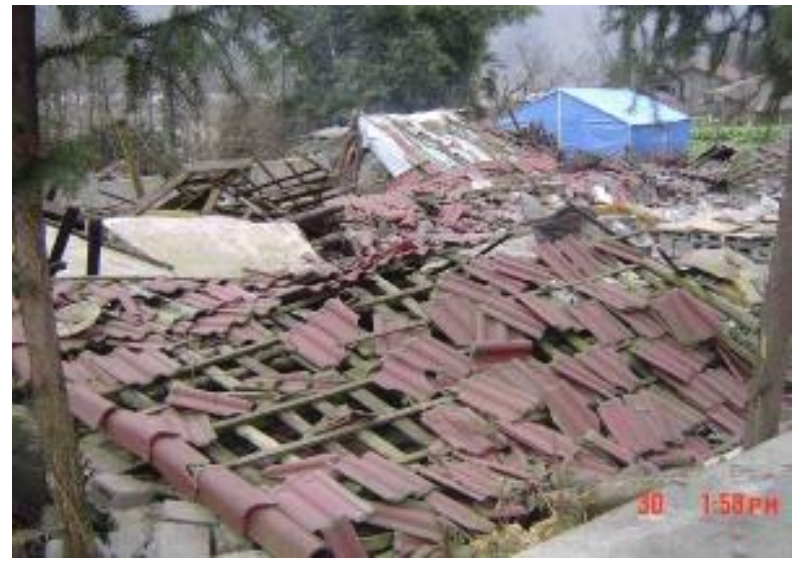

Fig.1 Complete collapse of brick-wood structure

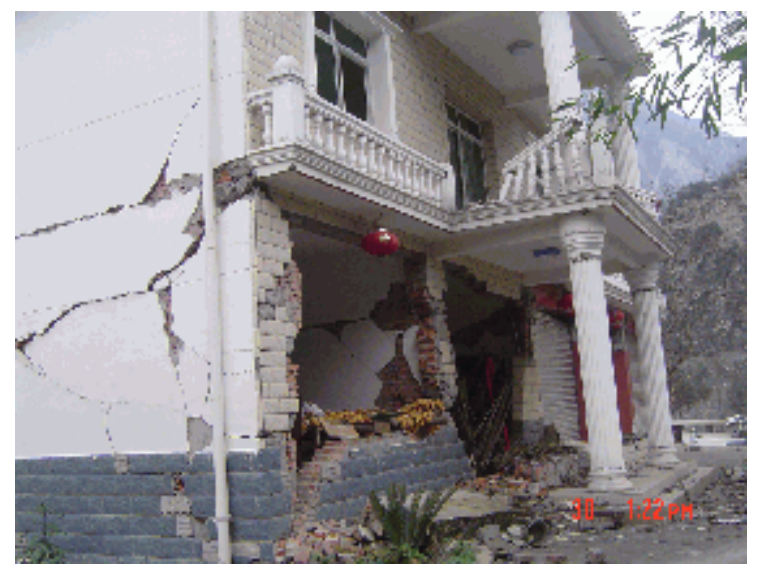

Fig 2 Earthquake disaster characteristics of brick-concrete structure

\section{Brick concrete structure}

Brick concrete structure generally refers to the building form which is constructed from the vertical load-bearing structure of the walls, and column, beam, floor slab, roof slab structure are constructed by reinforced concrete. The floor of building is no more than 6 layers. In recent years, the structure of buildings is more common in villages and towns. The structure is commonly built by 2-3 layers, which utilize brick or block wall to bear the weight of the housing, assembled with the construction of cast-in-situ reinforced concrete columns, beams and slabs. Although the wall bricks are brittle materials with poor performance of tensile, bending and shear, in recent years brick-wood structure has certain seismic structures, namely reinforced concrete columns along the vertical direction, reinforced concrete ring beam along the horizontal direction, and making structural columns and ring beams together. Its purpose is to strengthen the overall stiffness of the structure, to avoid brittle failure and to improve the seismic capacity of buildings.

\section{Damage characteristics}

The overall destruction of brick concrete structure is light, the damage is mainly as follows: the load-bearing wall appear " $\mathrm{X}$ " cracks, even partial collapse; structural column damage or even individual column bending fracture; beam bending, even damage; cast or prefabricated stairs damage, even the overall collapse; precast floor collapse; the connection between individual wall and column is broke; filler wall body crack, etc. (Fig 2); roof parapet, wall, corridor railings and other affiliated structure are structural damaged(Figure 3). The body of this kind structure can keep erect, and have certain seismic performance.

\section{Earthquake damage analysis}

Brick concrete structure is a kind of main structural form in the Chinese town in recent years. Compared with brick-wood structure, its seismic performance is better. In the place of the earthquake disaster investigation ( $\mathrm{X}, \mathrm{XI}$ earthquake intensity areas), this kind of building structure 
mainly has the following characteristics of damage:

(1) Lack of reinforcement and cross section of cast-in-place component

Most of the buildings have certain anti-seismic structural design, which are assembled with cast-in-place reinforced concrete column and beam, but due to insufficient reinforcement, or no enough cross section of component, components of this structure can be lead to stress failure and fracture, and cannot to effectively resist earthquake damage(Fig 4, fig 5).

(2) Poor shear strength of walls

A large number of buildings seem to be erect and intact, in fact, the load-bearing walls have more serious shear damage, with a large number of " $\mathrm{X}$ " shaped cracks (Fig 6), and even collapse, the overall structure of the building is severely damaged. Because shear strength of the brick and masonry wall is poor, and there is no tiebars between the walls, the walls and the floors, connectivity between the walls and the other components is failure during the action of seismic shear force and vertical loads. When the tensile stress of walls is larger than its strength, load-bearing wall will have diagonal cracks or "X" shaped cracks.

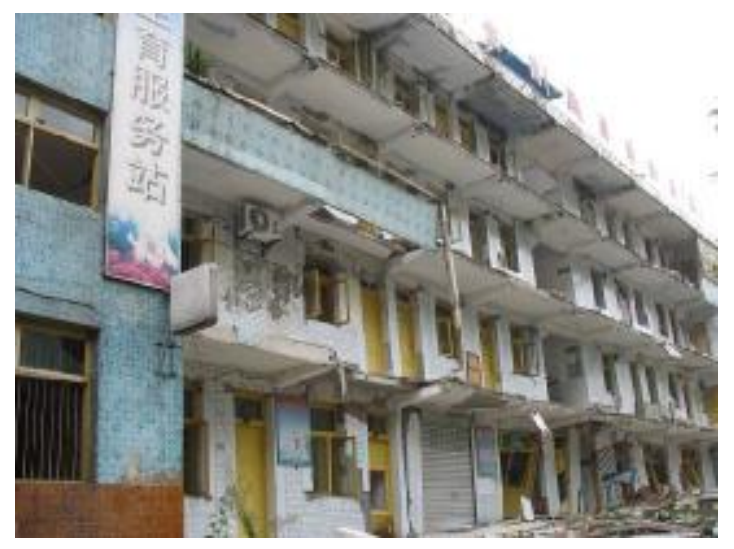

Fig 3 Brick fence in outside corridor of office building collapsed

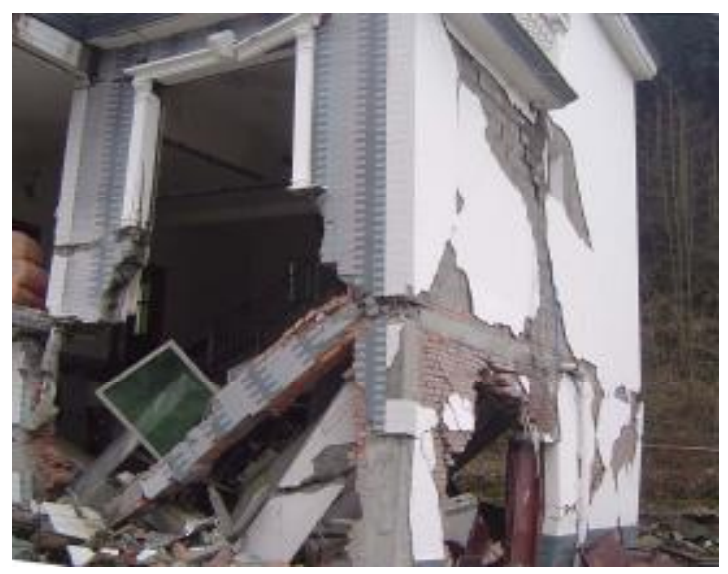

Fig 5 Loading failure of ring beam

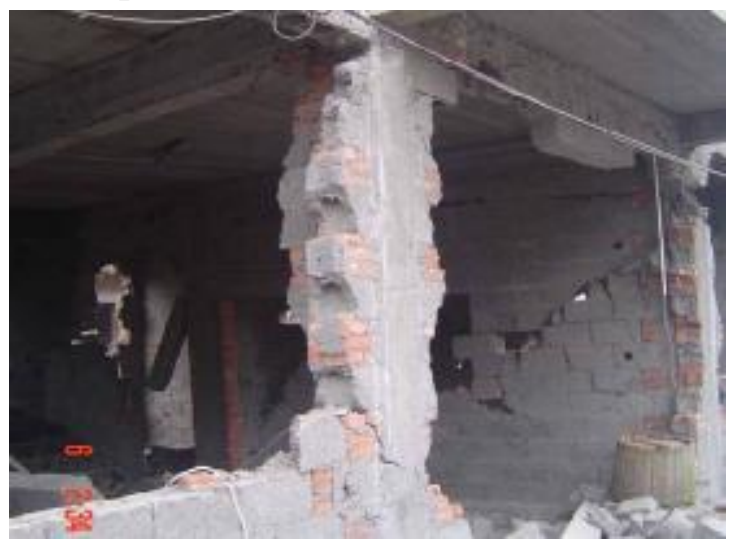

Fig 4 Loading failure of constructional column

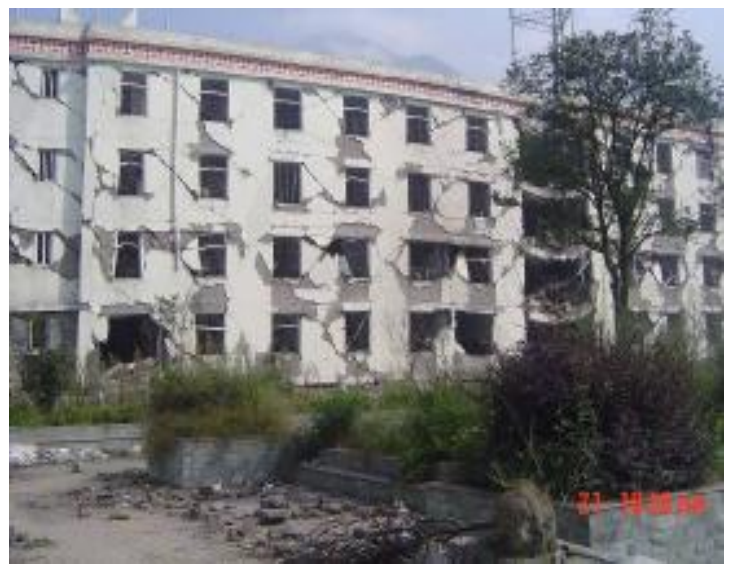

Fig 6 Dormitory of Yingxiu middle school suffered "X" shear cracks

(3) The use of precast floor slab

For most of the brick concrete structure, the top floor slab is made of cast-in-place reinforced concrete slab, but considering the economic reasons, non-top floor slab still mostly adopt precast floor Because of the connection between precast floor slabs and beams, and walls is very fragile, this connection is easy to cause instability, resulting in progressive collapse of overlapping of multiple floors (Fig 7).

\section{Brick-concrete structure of bottom frame}

Brick-concrete structure of bottom frame is still a special form of brick-concrete structure, which upper structure is brick and concrete structure, and bottom structure is frame structure. 
This structure is a kind of special structure of the current economic conditions of our country. In order to meet the requirements of the use, bottom of street residential, office buildings and other buildings need large space, so brick-concrete structure of bottom frame is adopted. This structure has characteristics of "top-heavy", "rigid top and soft bottom", so it is unfavorable from the Seismic factor. But because of the convenience and flexibility of its use, this structure is widely used in our country at present.

\section{Damage characteristics}

Brick-concrete structure of bottom frame is overall heavily damaged, in addition to damage characteristics similar to brick-concrete structure, the most serious damage phenomenon is: destruction or collapse of the whole building structure caused by collapse and tilt of bottom frame. It is basically embodied in: seriouse damage of columns of bottom frame, filling wall collapse(Fig. 8), even the whole structure collapse (Fig 9), so the seismic performance of the buildings structure of is very poor.

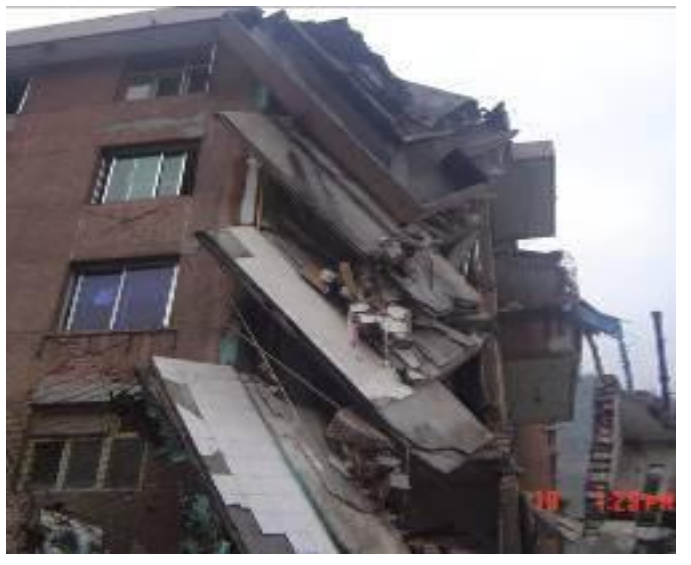

Fig 7 Domino effect triggered by prefabricated slabs

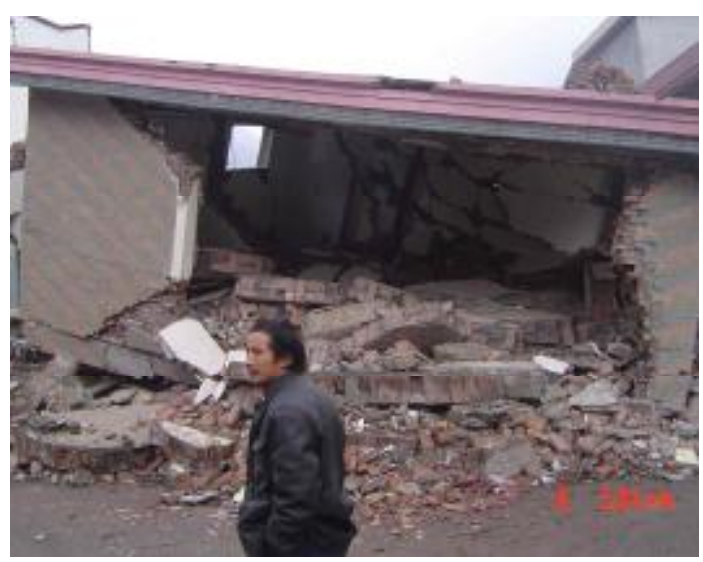

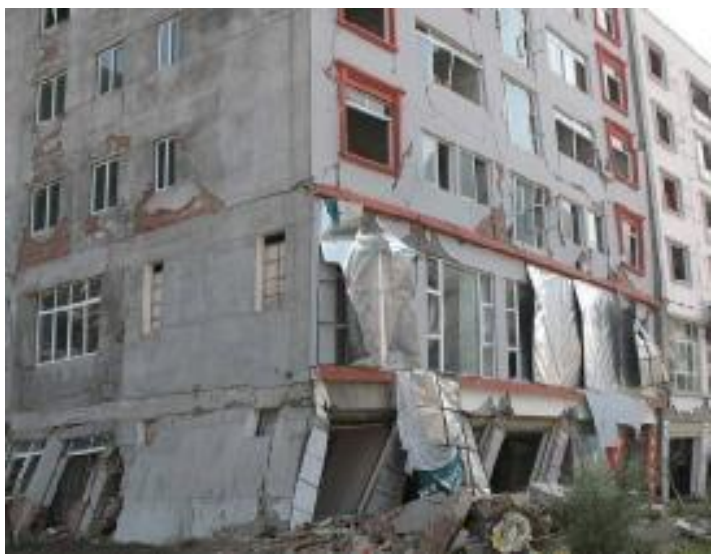

Fig 8 Brick-concrete structure of bottom frame with serious damage

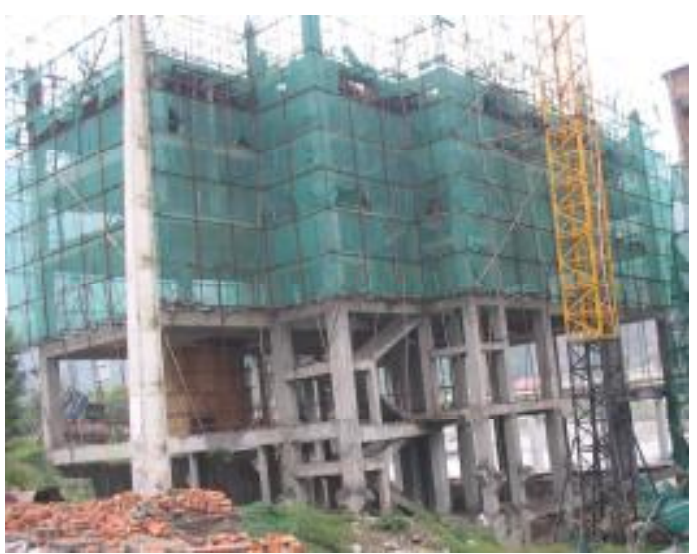

Fig 9 Integral collapse of brick-concrete structure of bottom frame

Fig 10 Earthquake disaster characteristics of reinforced concrete frame structure

\section{Earthquake damage analysis}

As for brick-concrete structure of bottom frame, because bottom framework materials of the structure are different from the upper materials of brick-concrete, the structure is composed of two kinds of load-bearing and anti-lateral force system. Because that bottom frame and upper wall stiffness influence on structure under earthquake force and deformation are more prominent, resulting in discontinuous structural strength and stiffness. This discontinuity will cause excessive 
stress concentration at local weak parts, and make the structure serious damage or even collapse (Fig 8, fig 9). Therefore, seismic performance of the structure is very poor, and this structure system should be avoided in earthquake high intensity area as much as possible.

\section{Reinforced concrete frame structure}

Reinforced concrete frame structure is generally the structure which beams can connect columns with rigid or hinged connections, and form bearing system, namely framework built by beam and column can resist horizontal and vertical load in the process of application. The wall of this structure is not load-bearing, only plays the role of surrounding and separating. This structure is commonly used for multiple public buildings less than 10 stories, such as office buildings, shopping malls and so on. In the non-seismic region, this structure is also used in high-rise building. Its structure form is shown in Fig 10, namely a frame structure in the construction in Beichuan County. Its structural characteristics are clear: overall frame has been built, but filled wall is not still completed. Advantage of this structure is large indoor space, so that it can meet the complex forms, and the room can be arbitrarily split. Although the weight of the structure is larger, but its ductility is better, it can withstand greater deformation. In the earthquake, its seismic performance is better than the brick-concrete structure's, but seismic performance of this structure is worse than shear wall structure and frame structure's, even worse than steel structure's.

\section{Damage characteristics}

In meizoseismal area of Yingxiu Town and Beichuan County, due to the earthquake intensity's reaching 11 degrees, a lot of reinforced concrete frame structures were severely damaged. Damage degree of reinforced concrete frame structure was small in others earthquake affected area. The damage was mostly embodied in: non-load bearing wall shear crack (Fig 11), even partial collapse or overall collapse; the stigma and the base damage (Fig 9): crack of concrete frame columns, and reinforced concrete columns exposure; column concrete crush, longitudinal reinforcement bending; collapse of underlying structure collapse, the whole floor or overall collapse (Fig 12, fig 13).

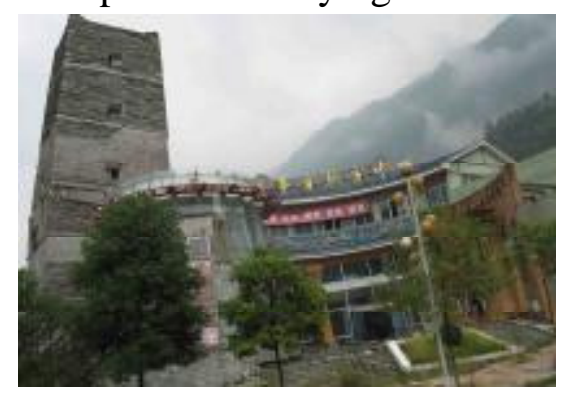

Fig 11 Top titt and wall cracks of Beichuan social service center
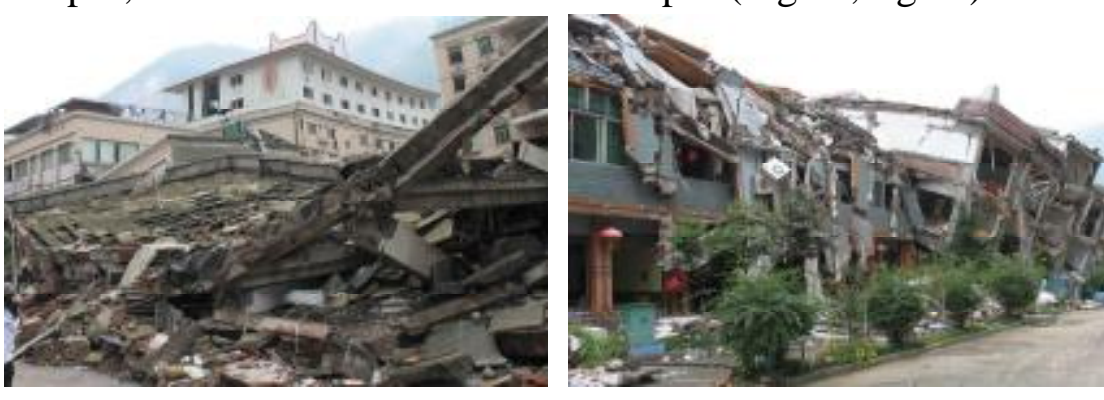

Fig 12 Partial collapse of Beichuan Hotel Fig 13 The collapse of a three-story frame structure in Beichuan County

\section{Earthquake damage analysis}

The reinforced concrete frame structure is a relatively strong seismic performance structure. In earthquake disaster investigation (X, XI earthquake intensity area), the buildings are able to erect, not completely collapsed, but the structure has some damage characteristics, mainly in the following aspects:

(1) Damage of infilled walls

As for the frame structures we observed, the most prominent damage feature is the destruction of filler wall. Its appearance looks like intact structure; actually its non-bearing wall has produced serious shear damage with large number of diagonal cracks or " $\mathrm{X}$ " cracks (Fig 11), it will cause 
more serious person safety and property loss. The reason is that shear strength of the brick and masonry wall is poor, and in the earthquake shear force and vertical load, the connection between the walls and other various components will be failure due to lack of tie bar between the walls of the masonry structure, and the walls and the frame beams and columns. If the tensile stress exceeds its strength, the walls will produce oblique or skew cracks. But the destruction of the infilled wall can also absorb a large number of seismic energy in the earthquake, and serve as the first seismic line of whole framework, delaying destruction of main frame.

(2) Damage of beams and columns

In the observation spot, the destruction of the column is mostly manifested as: cracks and damage of concrete of column end, reinforcement exposure, column collapse, stirrup failure; the destruction of the beam is mostly manifested as: the surface layer of concrete beam crack, reinforcement exposure, etc. Fig 10 shows a frame structure of constructed in Beichuan County, and beam-column joints of the overall framework are cracked and the reinforcement is exposed. On the whole, the damage of the column is more serious than that of the beam. The main reason is that stiffness ratio of beam to beam is out of proportion, not to achieve the "strong column and weak beam" design purpose, it may even lead to more serious damage, namely collapse of whole layer or the whole building collapse. The main reason for the destruction of the concrete column is: the longitudinal reinforcement of the column is not enough to bend yielding and can form a plastic hinge, when earthquake occurs; insufficient strength of concrete; confined longitudinal reinforcement failure because of too small diameter of column stirrup.

(3) The whole layer of top or bottom collapsed or whole collapsed

The whole layer collapse often occurs in change layer of lateral stiffness of structure, such as building top or bottom layer, or variable cross-section layer. It is mainly due to stress concentration of local layer caused by lateral stiffness change of the structure. The main reason of overall collapse is due to bearing structure failure caused by load bearing column failure, mostly belonging to the "strong beam weak column" type.

\section{Statistical analysis of damage degree of buildings with different structural types}

According to nation classification "Gradation Criterion of Earthquake Damage to Buildings (1990)" (Anti-built No.377) [9], the earthquake damage of buildings can be divided into five grades of basically intact, minor damage, moderate damage, severe damage and collapse. According to above standard, statistical damage situation of different types of residential buildings in the investigation of typical points (such as Qipan Village, Qing Ping Town, Yanjing Village, Yingxiu Town, Beichuan County), as shown in Table 1. 
Tab 1 Statistics on the damage degree of various types of residential buildings (incomplete statistics)

\begin{tabular}{|c|c|c|c|c|c|c|}
\hline $\begin{array}{l}\text { investigation } \\
\text { point }\end{array}$ & $\begin{array}{l}\text { structure type } \\
(\text { percentage/\%) }\end{array}$ & $\begin{array}{l}\text { basically } \\
\text { intact }\end{array}$ & $\begin{array}{l}\text { minor } \\
\text { damage }\end{array}$ & $\begin{array}{l}\text { moderate } \\
\text { damage }\end{array}$ & $\begin{array}{l}\text { severe } \\
\text { damage }\end{array}$ & collapse \\
\hline \multirow{2}{*}{$\begin{array}{l}\text { Qipan Village, } \\
\text { Qing Ping Town }\end{array}$} & Brick-wood structure & 0 & 0 & 7 & 12 & 81 \\
\hline & $\begin{array}{l}\text { Brick-concrete structure } \\
\text { (bottom frame) }\end{array}$ & 0 & 9 & 22 & 30 & 48 \\
\hline \multirow{2}{*}{$\begin{array}{l}\text { Yanjing Village, } \\
\text { Qing Ping Town }\end{array}$} & Brick-wood structure & 0 & 0 & 0 & 12 & 88 \\
\hline & $\begin{array}{l}\text { Brick-concrete structure } \\
\text { (bottom frame) }\end{array}$ & 0 & 11 & 23 & 27 & 50 \\
\hline \multirow{2}{*}{ Beichuan County } & $\begin{array}{l}\text { Brick-concrete structure } \\
\text { (bottom frame) }\end{array}$ & 0 & 0 & 0 & 32 & 68 \\
\hline & $\begin{array}{l}\text { reinforced concrete frame } \\
\text { structure }\end{array}$ & 0 & 0 & 7 & 48 & 45 \\
\hline \multirow{2}{*}{ Yingxiu Town } & $\begin{array}{c}\text { Brick-concrete structure } \\
\text { (bottom frame) }\end{array}$ & 0 & 0 & 0 & 51 & 48 \\
\hline & $\begin{array}{l}\text { reinforced concrete frame } \\
\text { structure }\end{array}$ & 0 & 0 & 11 & 51 & 38 \\
\hline
\end{tabular}

According to the investigation of building damage (observation and consultation) and preliminary results, a preliminary understanding of all kinds of typical residential building damage is obtained. Among them, the collapse rate of brick-wood buildings is the biggest, reaching 90\%, it is mainly that brick-wood buildings do not have any structural measures, and the performance of the overall structure is poor, and it is prone to structural damage under strong earthquake. The reinforced concrete frame structure is the best seismic performance buildings, in Yingxiu Town and Beichuan County (11 degrees meizoseismal area), a large number of reinforced concrete frame structures were seriously damaged, but more than $50 \%$ of the buildings did not collapse still, so life and property safety were preserved. Preliminary analysis of different types of buildings in order from small to large is: reinforced concrete frame structure, brick-concrete structure, brick-wood structure.

\section{Seismic strengthening measures of buildings of different structural types}

According to seismic damage analysis of buildings of different structural types, the following seismic strengthening measures are taken for all kinds of structures.

\section{Brick-wood structure}

(1) Strengthen the mutual connection among the components of the building to make buildings have good integrity[10]; Pay attention to setting corner bar and reinforced concrete circle beam in order to enhance the overall seismic performance of housing and effectively curb local damage of the wall by uneven seismic action.

(2) Strengthen the quality of walls masonry and guarantee sufficient thickness of the walls to improve the shear strength of the walls.

\section{Brick-concrete structure}

(1) For the brick-concrete structure, according to the seismic code for seismic design of buildings, the corresponding measures of seismic resistance can be given: structure column, ring beam and floorslab of cast-in-place reinforced concrete, designing component cross sections and reinforcement parameters according to the specification requirements.

(2) Strengthen the quality of wall masonry to improve the shear strength of walls; and ensure the connection between wall and other components.

(3) Brick-concrete structure is strictly forbidden to use prefabricated floor slab in earthquake high intensity area. 


\section{Brick-concrete structure of bottom frame}

(1) Try not to adopt the stiffness discontinuous structure system like brick-concrete structure of bottom frame.

(2) If this structure must be adopted due to constraints of planning and funding, the buildings need to be designed and constructed strictly in accordance with relevant regulations. The key measure is not to adopt pure frame structure, as for bottom frame part of this kind of structure. Seismic walls in two directions must be set to form frame-seismic wall structure, and the seismic walls are arranged to symmetrical.

(3) The measures of strengthening the angle steel of the bottom frame column and the constructional column and strengthening the haunch of the bottom frame beam can be taken.

\section{Reinforced concrete frame structure}

(1) Strengthen the quality of wall masonry to improve the shear strength of walls, and ensure the connection between the walls and other components.

(2) Determine the stiffness ratio of the frame structure reasonably, and avoid the collapse of the partial structure caused by the local layer stress concentration caused by the change of the lateral stiffness of the structure.

(3) For the frame structure, the seismic design and construction should guarantee the ductility of frame of "strong column and weak beam" in order that the beam is the first line of defense, and the column is the second line of defense, so as to avoid the destruction of columns before the beams, and realize original design of "strong column and weak beam".

\section{Conclusions}

Through the investigation and discussion of damage characteristics of main types of structures, earthquake damage information of different structural types of buildings are done, and aseismic reinforcement measures for all kinds of buildings are given further in this paper. The main conclusions are as follows:

1. Different types of buildings in Western Sichuan town are put in order by damage degree from small to large: reinforced concrete frame structure, brick-concrete structure, brick-wood structure. It is suggested that the frame structure and brick concrete structure with seismic measures should be adopted.

2. Brick-wood structure is still a common structure form of China rural, but seismic performance of this kind of building is poor because of having no seismic design and poor integrity and shear resistance. so, this type of structure shall not be used as far as possible in seismic areas.

3. Brick-concrete structure which can have certain seismic resistance measures and good quality of construction is relatively better. To ensure that structural column, beam, floor slab and other components of cast-in-place reinforced concrete are configured for brick-concrete structure reasonably; strengthen the shear strength of the wall; avoid adopting brick-concrete structure of bottom frame and using prefabricated floor slab in earthquake high-intensity area.

4. Reinforced concrete frame structure is a kind of structure of relatively strong seismic resistance performance. Its seismic design and construction should guarantee the ductility of frame of "strong column and weak beam". The shear strength of the infill wall should be increased to ensure the connection between the walls and the other components.

\section{Acknowledgements}

This work was financially supported by the Shandong Natural Science Foundation (ZR2014DQ022). 


\section{References}

[1] Guo T T, Xu X W, Yu G H, et al. 2009. Investigation and analysis of earthquake disasters for rural residential buildings in Western Sichuan areas[J]. Journal of Architecture and Civil Engineering (2009), 26(3): 59-64.

[2] Guo T T, Yu G H, Xu X W. Characteristics of Wenchuan earthquake disasters and Discussion on Causes of Buildings Damage[J]. Earthquake Resistant Engineering and Retrofitting(2010), 32(4): 125-133.

[3] Yang Y Q, Gong M S, Xie L L, et al. Analysis on seismic damage characteristics of dwellings in Lushan 7.0 earthquake[J].Building Structure(2014), 18: 68-70.

[4] Wang M S, Zhao X M, Ji X D, et al. Earthquake resistant behavior on seismic strengthening of typical rural brick-wood structure in Beijing[J]. Journal of Chongqing Jianzhu University(2015), 37 (6) :1-8.

[5] Qian F F, Qian K, Gu W H, et al. Experimental Study on the Seismic Strengthening Method for Typical Masonry-Timber Structures[J]. Journal of Huaiyin Institute of Technology (2015), 24 (5) : 47-51.

[6] Wang Y L, Yang Q H, He Z M. Seismic performance analysis on rural building of 7.22 earthquake[J]. Sichuan Building Science(2015), 41(4):62-65.

[7] Chen D Z, Zhao S S, Chen R Application and Analysis of Seismic Isolation Technique in Gym Reinforcement [J]. Earthquake Resistant Engineering and Retrofitting (2016), 38 (2) : 1-6.

[8] Han B K, Zhang L Q, Li C X. Disaster analysis and control countermeasures of brick-wood structure type protective buildings[J], Journal of Natural Disasters (2008), 13(6):105-111.

[9] The Ministry of Housing and Urban-Rural Development of the People's Republic of China. Gradation Criterion of Earthquake Damage to Buildings (1990)(Anti-built No.377)[Z].

[10] Wan J, He M, Guo H. Reflection on the seismic fortification and design in light of the Wenchuan Earthquake. Journal of Xi'an University of Architecture \& Technology(Natural Science Edition)(2008), 40(5): 631-636. 